\title{
Novel Method of Liposuction in Primary Lymphedema
}

\author{
Chirra Likhitha Reddy, Ravi Kumar Chittoria*, Abhinav Aggarwal, Saurabh Gupta, Padma Lakshmi Bharathi Mohan, Shijina K, Imran \\ Pathan.
}

Department of Plastic Surgery, India.

*Corresponding Author: Ravi Kumar Chittoria, Department of Plastic Surgery Jawaharlal Institute of Postgraduate Medical Education and Research (JIPMER) Pondicherry India-605006.E-mail:drchittoria@yahoo.com

Received date: December 02 2019; Accepted date: December 09, 2019; Published date: December 15, 2019

Citation: Chirra L Reddy., Ravi K Chittoria., Devi P Mohapatra., Dinesh kumar S., Friji M T. (2019) Novel Method of Liposuction in Primary Lymphedema. International Journal of Clinical Case Reports and Reviews. 1(1); DOI: 10.31579/2690-4861/003

Copyright: () 2019 Ravi Kumar Chittoria, This is an open-access article distributed under the terms of the Creative Commons Attribution License, which permits unrestricted use, distribution, and reproduction in any medium, provided the original author and source are credited.

Abstract
Chronic lymphedema is a devastating problem for the patient and major financial and social burden.
There are various medical and surgical management options available. One of the methods of treatment
of chronic lymphedema is liposuction. We have used a novel modification of liposuction adhering to the
principles to help in better aspiration of fat and fluid.
Keywords: primary lymphedema; liposuction; power-assisted liposuction (pal)

\section{Introduction}

Lymphedema is a chronic and important cause of lower limb swelling which is difficult to treat [1]. There are have been various treatment options to reduce size depending on the stage of the disease. Medical options include Complex Decompressive Therapy (CDT), compression garments, massage, elevation, exercise, Low-level LASER therapy (LLLT). Various drugs have been used both to treat the primary infection, prevent secondary infection and to reduce the limb circumference such as diethylcarbamazine, albendazole, diuretics, benzopyrones, various antibiotics (to treat and prevent secondary infections) etc. Surgical treatment includes both physiological and reductive or ablative procedures [2].

Physiological procedures may be lymphaticovenous shunt, nodovenous shunt, vascularised lymphnode transfer etc. In cases where these fail or may not be available, ablative procedures like liposuction, Charles procedure or Thompson procedure may be done.

Conventionally as mentioned in literature multiple incisions are by circumferential incisions in axial plane [3] (figure1) this can leave out few blindspots.

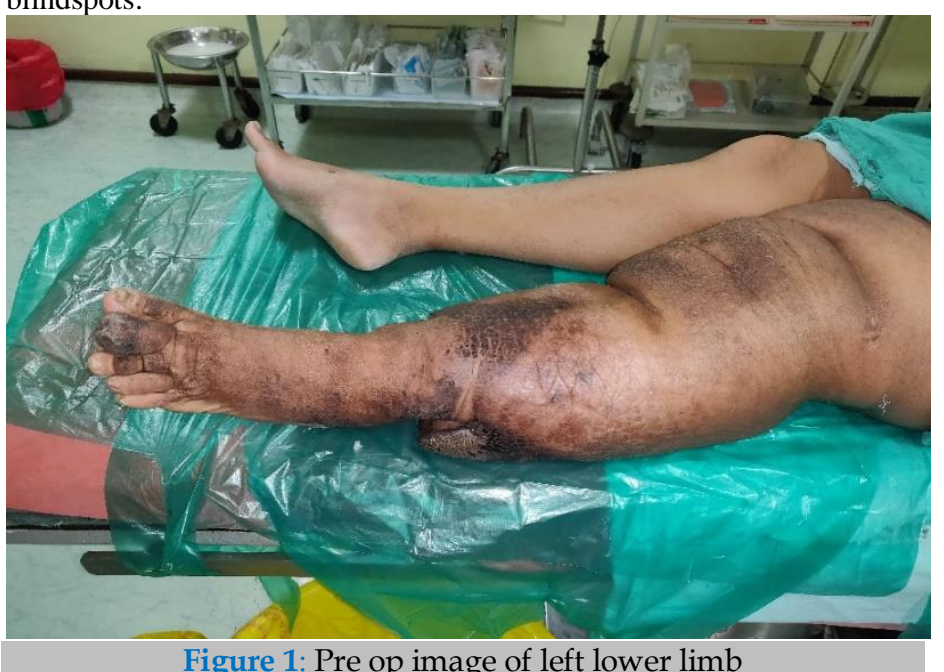

Figure 1: Pre op image of left lower limb
We would like to discuss the novel technique of liposuction done in our patient as a part of our treatment.

\section{Methodology}

The present study was conducted in department of plastic surgery in a tertiary care hospital. The case under study is a 29 - year female patient presented with history of swelling of the left lower limb for 16 years duration without involvement of genitalia. Thorough evaluation of the patient done with lymphoscintigraphy, CT arteriography and venography, MRI of the affected limb. Limb volume measurement recorded pre operatively with volume displacement technique and tape measurements of the affected limb done.

Under tourniquet control 2 liters of standard tumescent solution was injected into the left lower limb using infiltration cannula. Power-assisted liposuction is used. Ten 3-mm-long incisions are made over the limb on the lateral aspect to facilitate infiltration and later suctioning of the fat was done (figure 2). First the postero-lateral midline of the limb was marked and three incisions made along this line on the leg and three on the thigh. $3 \mathrm{cms}$ below this line another line was drawn parallel to it where two incisions marked to give a zig-zag pattern. Liposuction was performed using 15 and $25 \mathrm{~cm}$ long cannulas with diameters of 3 and $4 \mathrm{~mm}$ (figure 2-3).

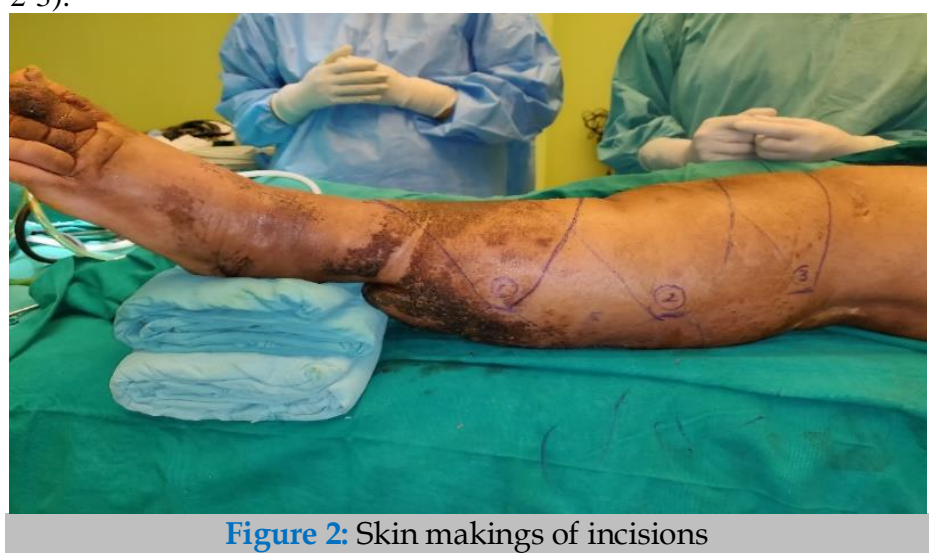




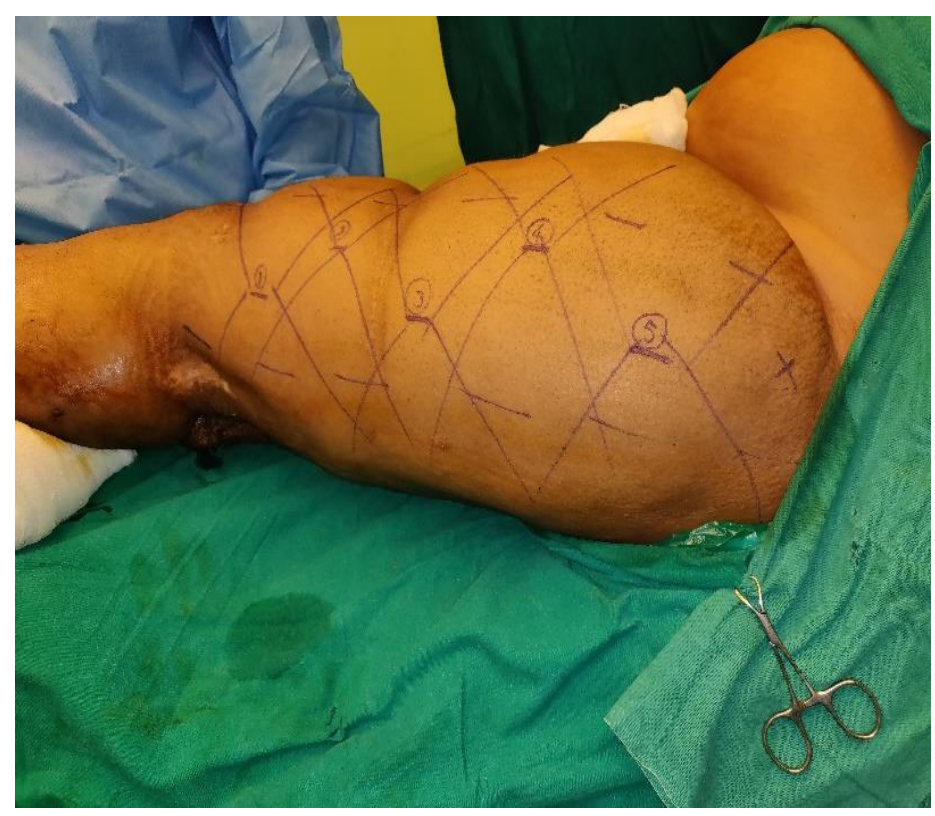

Figure 3: Skin marking with modified incisions

About $1.5 \mathrm{~L}$ of lipoaspirate was removed from the affected limb. Ports were left open for draining the fluid. Compression bandage was applied which was changed once every three days (figure 4).

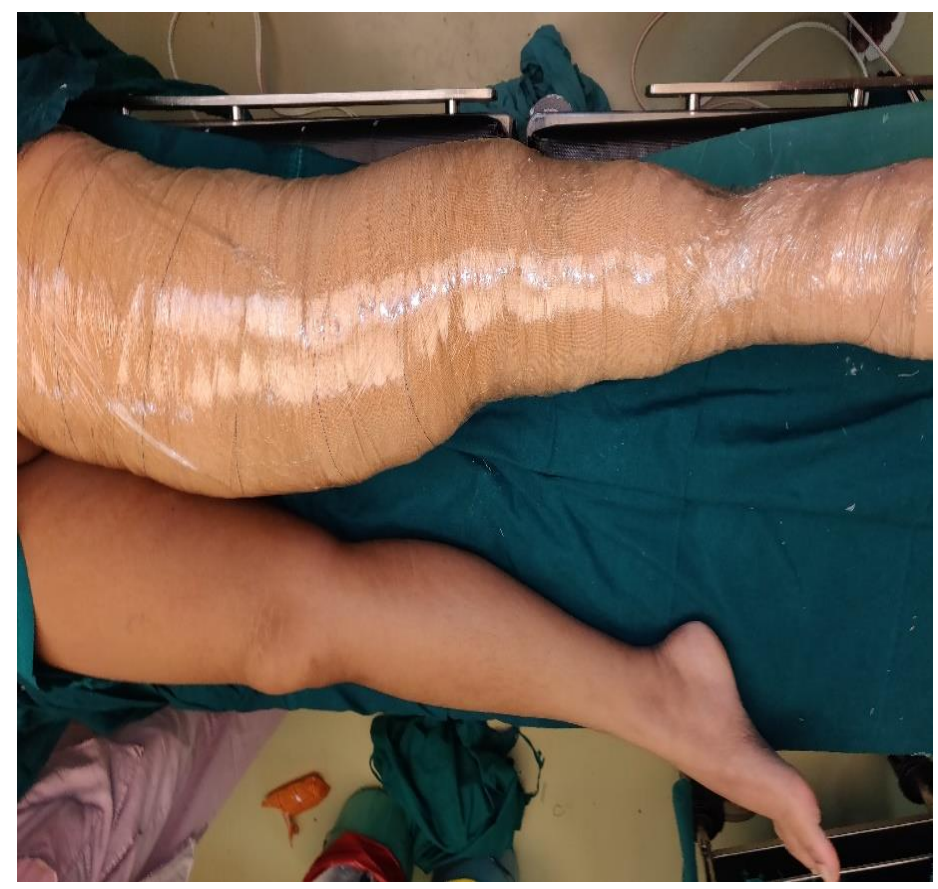

Figure 4: Compression bandage applied.

\section{Results}

Reduction of limb size was noted in the immediate post-operative period. Quantification of the same was done with limb girth measurements. A difference of $2 \mathrm{cms}$ was noted. (Figure $1 \& 5$ ) Patient did not develop any complications.

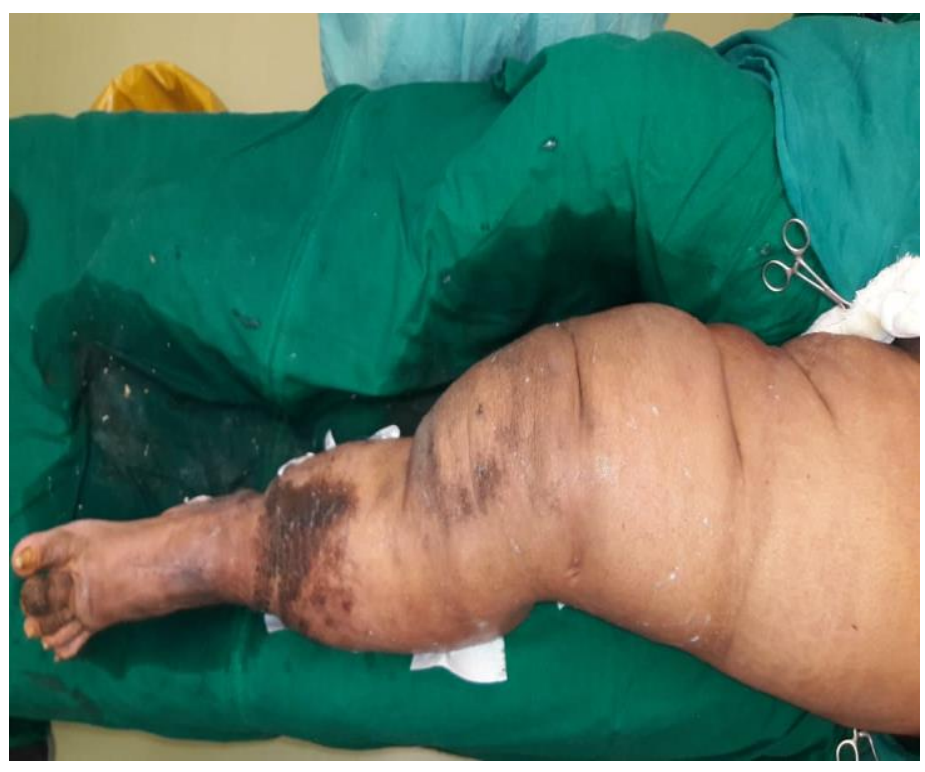

Figure 5: Limb after liposuction

\section{Discussion}

Chronic lymphedema treatment may be combined with liposuction along with other conservative modalities when physiological procedures are not adequate or are not feasible. Liposuction for lymphedema is performed axially with respect to the axis of the limb. This will prevent damage to the existing lymphatic vessels within the limb.

Greene et al evaluated the effects of liposuction in one patient with primary lymphedema affecting the leg, and two patients with secondary lymphedema [4]. Postoperative lymphoscintigraphy revealed that two of the patients had reduced dermal backflow, and one had new transit and uptake of tracer to epitrochlear nodes. Using bioimpedance spectroscopy, Boyages et al found that after liposuction for lymphedema the extracellular fluid was reduced, suggesting improved flow of the lymphatic fluid [5]. Together these studies suggest that lymphatic fluid transport may actually improve following liposuction. Another study investigating the effect of liposuction on skin blood flow in patients with lymphedema using laser Doppler imaging found that skin blood flow increased significantly to values similar to the normal arm following liposuction [6]. The reduced incidence of cellulitis may be explained by the improvement in lymphatic fluid flow and skin blood flow following liposuction. In a recent study, liposuction in 130 patients with arm lymphedema reduced the incidence of cellulitis from 534 bouts of cellulitis per 1,147 observation years before to 60 bouts of cellulitis per 983 observations years after liposuction, a reduction of 87\% [7]. The possible complications include bleeding, skin necrosis, infection, etc.

All these studies support the role of liposuction in lymphedema patients. In the classical description given it is noted that the liposuction has to be done axially and circumferentially along the limb. This might cause few blind spots to be left out between the incisions. Hence we have used incisions as steps (zig-zag manner) to help in crosshatching and preventing blind spots.

\section{Conclusion}

We have devised a novel way of doing liposuction in lymphedema in achieving better ans effective results.

However large, randomized control trials are required to substantiate the results. 


\section{Declarations}

\section{Acknowledgments}

\section{Authors' contributions}

All authors made contributions to the article

\section{Availability of data and materials}

Not applicable.

Financial support and sponsorship

None.

\section{Conflicts of interest}

None.

\section{Consent for publication}

Not applicable.

\section{Copyright}

(c) The Author(s) 2019.

\section{References}

1. Avraham T, Quartararo PJ, Daluvoy SV, Mehrara BJ. (2009) Cellular and Molecular Mechanisms of Lymphangiogenesis and Lymphedema. Current Cancer Therapy Reviews. Feb 1; 5(1):28-36.

2. Executive Committee. The diagnosis and treatment of peripheral lymphedema: 2016 consensus document of the Interntional Society of Lymphology. Lymphology. 2016 Mar 21; 49(4):170-184.

3. Hoffner M, Ohlin K, Svensson B, Manjer J, Hansson E, Troëng T, Brorson H. (2018) Liposuction Gives Complete Reduction of Arm Lymphedema following Breast Cancer Treatment-A 5-year Prospective Study in 105 Patients without Recurrence. Plastic and Reconstructive Surgery Global Open. 6 (8).

4. Brorson H, Svensson H, Norrgren K, Thorsson O. (1998) Liposuction reduces arm lymphedema without significantly altering the already impaired lymph transport. Lymphology. 31 (04):156-172. [PubMed] [Google Scholar]

5. Greene A K, Voss S D, Maclellan R A. (1788-1789) Liposuction for swelling in patients with lymphedema. N Engl J Med. 2017;377(18): [PubMed] [Google Scholar]

6. Brorson H, Svensson H. (1997) Skin blood flow of the lymphedematous arm before and after liposuction. Lymphology. 30 (04):165172. [PubMed] [Google Scholar]

7. Lee D, Piller N, Hoffner M, Manjer J, Brorson H.(2016)Liposuction of postmastectomy arm lymphedema decreases the incidence of erysipelas. Lymphology. 49:8592. [PubMed] [Google Scholar] 